\title{
Phenotypic Multiple Antigen Bead-based Multiplex Assay
}

National Cancer Institute

\section{Source}

National Cancer Institute. Phenotypic Multiple Antigen Bead-based Multiplex Assay. NCI Thesaurus. Code C130178.

A type of solid-phase multiplex assay that uses microbeads coated with recombinant or infinity purified antigens from multiple alleles for the detection and identification of antibodies that would bind and react to these antigens. 